\title{
Eotaxin-1 in exhaled breath condensate of stable and unstable asthma patients
}

\author{
Ziemowit Zietkowski ${ }^{*}$, Maria M Tomasiak-Lozowska', Roman Skiepko', Elzbieta Zietkowska², \\ Anna Bodzenta-Lukaszyk ${ }^{1}$
}

\begin{abstract}
Background: Airway eosinophilia is considered a central event in the pathogenesis of asthma. Eotaxin plays a key role in selective eosinophil accumulation in the airways and, subsequently, their activation and degranulation. The study was undertaken to evaluate eotaxin-1 levels in the exhaled breath condensate (EBC) of asthmatics with different degrees of asthma severity and to establish the possible correlation of these measurements with other recognized parameters of airway inflammation.

Methods: EBC was collected from 46 patients with allergic asthma (14 with steroid-naïve asthma, 16 with ICStreated, stable asthma, 16 with ICS-treated unstable asthma) and 12 healthy volunteers. Concentrations of eotaxin-1 were measured by ELISA.

Results: In the three groups of asthmatics, eotaxin-1 concentrations in EBC were significantly higher compared with healthy volunteers (steroid-naive asthma: $9.70 \mathrm{pg} / \mathrm{ml} \pm 1.70$, stable ICS-treated asthma: $10.45 \pm 2.00$, unstable ICS-treated asthma: $17.97 \pm 3.60$, healthy volunteers: $6.24 \pm 0.70$ ). Eotaxin-1 levels were significantly higher in patients with unstable asthma than in the two groups with stable disease. We observed statistically significant correlations between the concentrations of eotaxin-1 in EBC and exhaled nitric oxide $\left(F_{E N O}\right)$ or serum eosinophil cationic protein (ECP) in the three studied groups of asthmatics. We also discovered a significantly positive correlation between eotaxin-1 in EBC and blood eosinophil count in the groups of patients with unstable asthma and steroid-naïve asthma.
\end{abstract}

Conclusions: Measurements of eotaxin-1 in the EBC of asthma patients may provide another useful diagnostic tool for detecting and monitoring airway inflammation and disease severity.

\section{Introduction}

Asthma is a chronic inflammatory disease of the airways. Eosinophils play a crucial role in the pathogenesis of asthma, and eosinophil infiltrations prevail in sites of allergic inflammation. The most important factors taking part in the development of inflammatory infiltration are increased expression of adhesion molecules localized on the surface of endothelial cells (VCAM-1 - vascular cell adhesion molecule-1) and increased synthesis of chemotactic substances by eosinophils and Th2 lymphocytes [1,2]. Many factors are known which increase eosinophil chemotaxis to the site of inflammation as well as prolonging their survival, e.g. IL-3, IL-5, GM-CSF

\footnotetext{
* Correspondence: z.zietkowski@wp.pl

'Department of Allergology and Internal Medicine, Medical University of Bialystok, Poland

Full list of author information is available at the end of the article
}

(granulocyte monocyte colony stimulating factor) [3]. They act together with selective chemokines of eosinophils, such as eotaxin, RANTES or MCP-4 (monocyte chemotactic protein-4). The strongest and the most specific chemoattractant is eotaxin $[1,2]$.

In previous studies it was revealed that eotaxin levels in BAL fluid were higher in asthmatics than in healthy controls $[4,5]$. Eotaxin concentrations in sputum were also significantly raised in moderate and severe asthma patients when compared with healthy controls [6]. However, these relatively invasive approaches are unsuitable for repeated monitoring of airway inflammation.

By contrast, exhaled breath condensate (EBC), collected by cooling exhaled air, is a noninvasive, easily performed, and rapid method for obtaining samples from the lower respiratory tract. There has been increasing interest in measuring $\mathrm{EBC}$, which is a very useful
C Biomed Central

(c) 2010 Zietkowski et al; licensee BioMed Central Ltd. This is an Open Access article distributed under the terms of the Creative Commons Attribution License (http://creativecommons.org/licenses/by/2.0), which permits unrestricted use, distribution, and reproduction in any medium, provided the original work is properly cited. 
method in the pathophysiology and evaluation of new strategies for the treatment of asthma - especially for the assessment of inflammatory mediators related to the bronchial epithelium [7]. However, the analysis of EBC is still in its experimental phase and there remain many methodological questions in this method [8].

Previous studies have revealed that eotaxin can be measured in the EBC of patients with asthma [9-11]. Ko et al reveal that eotaxin levels are higher in asthmatics treated with inhaled steroids than in steroid-naïve asthmatics or healthy controls. The authors suggest that exhaled chemokines may be potential non-invasive markers for assessing airway inflammation in asthmatics [9]. However, to confirm such usefulness for eotaxin, the establishment of correlations of its levels with other recognized markers in the assessment of eosinophilic inflammation is needed. Such data are not available so far in published studies.

We hypothesize that eotaxin-1 levels in EBC are associated with the level of severity of the disease and markers of airway inflammation in asthma.

The aim of the study was to assess eotaxin- 1 concentrations in the EBC of asthmatics with different degrees of asthma severity, and also to establish the possible correlation of these measurements with the other recognized parameters of airway inflammation.

\section{Material and methods}

\section{Study population}

The study was performed upon groups of 14 steroidnaïve allergic asthma patients; 16 patients, treated with inhaled corticosteroids (ICS) with stable allergic asthma; and 16 ICS-treated patients with unstable allergic asthma. Asthma was diagnosed according to the criteria recommended by the GINA 2006 [12].

The steroid-naïve asthmatics had not been treated with ICS. They were free from acute exacerbations and respiratory tract infections during the three months prior to the study. In this group of patients asthma was diagnosed recently, just before inclusion to the study (on the basis of symptoms and other recognized tests, such as reversibility test or/and bronchial provocation tests).

The patients with unstable ICS-treated asthma and stable ICS-treated asthma had a many-year history of asthma and anti-asthmatic treatment. In these patients asthma was diagnosed several years ago on the basis of typical symptoms, positive reversibility tests, or bronchial provocation tests. The patients with stable ICStreated asthma had been treated with low to medium doses of ICS at a constant dose for at least three months. Stable asthma was defined as a minimal need for rescue medications (short-acting $\beta_{2}$-agonists), no exacerbations, and no use of systemic steroids in the previous 12 months. The patients with unstable asthma had required one or more hospitalizations for asthma and more than three oral steroid bursts in the last year. They had been taking high-doses of ICS and long-acting $\beta_{2}$-agonists for at least six months. Patients who had respiratory tract infections in the last month before the study were excluded from this study. All the patients were atopic and sensitized to common perennial inhaled allergens, as evaluated by skin prick tests (with commonly encountered aeroallergens: house dust mites, trees, weeds, grasses, cat, dog, Alternaria and Cladosporium).

12 healthy subjects were recruited for the study as a negative control group. In this group, asthma was excluded on the basis of lack of symptoms of asthma and atopy, normal spirometric indices, low exhaled nitric oxide $\left(\mathrm{F}_{\mathrm{ENO}}\right)$ levels, and no presence of eosinophilia in peripheral blood. Healthy volunteers also had a negative bronchial provocation test with histamine $\left(\mathrm{PC}_{20}>32 \mathrm{mg} / \mathrm{ml}\right)$. All healthy volunteers were non atopic; all of them had negative skin prick tests. They were free of respiratory tract infection within three months prior to the study and from other significant illnesses known to affect $\mathrm{F}_{\mathrm{ENO}}$ measurements. Asthma patients and healthy volunteers were non-smokers and during the last year had not been passive smokers.

\section{The scheme of the procedures during the study}

After inclusion to the study, the history of every patient with asthma was taken, then all patients were examined by the physician and blood (to determine serum total IgE, ECP, and blood eosinophil count) and EBC samples were collected. After $30 \mathrm{~min}$, the measurement of $F_{\mathrm{ENO}}$ level and spirometry were performed. Subsequently, all patients had skin prick tests. In healthy volunteers, all these procedures were carried out in the similar sequence. Finally, in all studied healthy subjects, a nonspecific bronchial provocation test with histamine was performed.

The study protocol was approved by the Ethics of Research Committee of the Medical University of Bialystok, number of agreement: R-I-002/265/2009. Informed consent was obtained from every patient entered in the study.

\section{Exhaled nitric oxide measurements}

Exhaled nitric oxide $\left(\mathrm{F}_{\mathrm{ENO}}\right)$ was measured by the chemiluminescence technique using a Sievers 280i NO Analyzer (Boulder, Colorado, USA). The measurements were performed at an expiratory flow of $50 \mathrm{ml} / \mathrm{s}$ according to ATS recommendations for on-line measurement of $\mathrm{F}_{\mathrm{ENO}}$ in adults [13]. 


\section{Lung function}

The spirometry $\left(\mathrm{FEV}_{1}\right)$ was performed using a MasterScreen Pneumo PC spirometer (Jaeger, Hoechberg, Germany), according to ATS standards [14].

\section{Collection of exhaled breath condensate}

EBC was collected by using a commercially available condenser (EcoScreen; Erich Jaeger $\mathrm{GmbH}$, Hoechberg, Germany) according to the current ATS/ERS guidelines [7]. All measurements were performed at the same time (between 8.00-10.00 am) to avoid possible circadian rhythm of mediator concentrations in EBC. All patients were asked to refrain from eating and drinking before collecting EBC. Exhaled air entered and left the chamber through one-way valves and an inlet and outlet, thus keeping the chamber closed. A low temperature inside the condensing chamber throughout the collection time produced a cooling down sample. The temperature of collection was around $0^{\circ} \mathrm{C}[7,15]$. Patients were instructed to breathe tidally for 10 minutes with nose clip. The respiratory rate ranged from 15-20 breaths/ minute. Patients were asked to swallow their saliva periodically and to temporarily discontinue collection if they needed to cough. At the end of collection 1.5 to $3.5 \mathrm{ml}$ aliquots of condensate were transferred to Eppendorf tubes and immediately frozen. Samples were stored at $-80^{\circ} \mathrm{C}[16]$.

The longest storage time of EBC samples did not exceed two months. The samples were not concentrated prior to measurement. All measurements were performed in a blind fashion. All samples were run in duplicate. Because the marker used to correct the difference in the degree of dilution has not yet been established, in our study we made no attempt to assess the dilution of ALF in EBC. The results (eotaxin-1) were well repeatable $\{\mathrm{CV}$ $(\%)=4-7 \%\}$. We performed the preliminary study, in which we measured eotaxin-1 in EBC immediately after collection and after 1,2 , and 3 months of storage at $-80^{\circ}$ $\mathrm{C}$ and we did not observe important changes. Therefore, we suggest that eotaxin -1 in $\mathrm{EBC}$ stored at $-80^{\circ} \mathrm{C}$ remains stable during at least three months.

\section{Measurements of eotaxin-1, ECP and other laboratory parameters}

Serum total IgE concentrations and serum ECP were measured using ImmunoCAP ${ }^{\mathrm{mi}}$ Technology (Pharmacia Diagnostics, Uppsala, Sweden). The minimum detectable level of ECP was $2.0 \mu \mathrm{g} / \mathrm{l}$. Blood eosinophil count was measured using a hematologic analyzer (Coulter Electronics GmbH, Miami, Florida, USA). The concentrations of eotaxin-1 (R\&D Systems, Wiesbaden-Nordenstadt, Germany) in EBC were determined using an enzymelinked immunosorbent assay. The minimum detectable level was $5.0 \mathrm{pg} / \mathrm{ml}$.

\section{Statistical analysis}

Statistical significance was analyzed by using analysis of variance (ANOVA) followed by Bonferroni's t test post hoc to determine statistical differences. All values were expressed as means \pm SD; $p$ values $<0.05$ were considered significant. The relationship between studied parameters was assayed by correlation. Pearson's linear correlation coefficient was used.

\section{Results}

Characteristics of patients and healthy volunteers are presented in table 1 (Table 1)

In the three groups of asthmatics, EBC concentrations of eotaxin-1 were significantly higher than those detected in healthy volunteers (steroid-naïve asthma: $9.70 \mathrm{pg} / \mathrm{ml} \pm 1.70$ [min. 7.56, $\max .12 .6$ ], $\mathrm{p}=0.002$; ICS-treated stable asthma: $10.45 \pm 2.00$ [min. 7.3, max. 13.8], $\mathrm{p}<0.001$; unstable ICS-treated asthma: $17.97 \pm$ 3.60 [min. 12.4, max. 24.5], $\mathrm{p}<0.001$; healthy volunteers: $6.24 \pm 0.70$ [min. 5.4, $\max .7 .3]$ ) (Figure 1). Eotaxin-1 levels were elevated in patients with unstable ICS-treated asthma compared with ICS-treated stable asthma $(\mathrm{p}=0.03)$ and steroid-naïve asthma patients $(\mathrm{p}=0.009)$. We observed a tendency toward slightly lower eotaxin-1 concentrations in steroid-naïve asthma patients compared with the ICS-treated stable asthma group ( $\mathrm{p}=0.52$ ).

We found statistically significant correlations between the concentrations of eotaxin- 1 in $\mathrm{EBC}$ and $\mathrm{F}_{\mathrm{ENO}}$ in the three studied groups of asthmatics. There were no correlations between eotaxin-1 in EBC and $F_{E N O}$ in the group of healthy volunteers (Figure 2). We discovered a significantly positive correlation between eotaxin-1 in EBC and serum ECP or blood eosinophil count in the groups of patients with unstable ICS-treated asthma and steroid-naïve asthma and between eotaxin-1 and serum ECP in the group of ICS-treated stable asthma (Figure 3 , Figure 4). Statistically significant correlations between eotaxin-1 in EBC and other studied parameters were not observed in any studied groups of asthmatics or healthy volunteers (Table 2).

Differences in eotaxin-1 levels (measured in duplicates) against the mean, using Bland and Altman statistics in the studied groups of asthmatic patients and healthy volunteers are presented in figure 5.

\section{Discussion}

Airway eosinophilia is recognized as a central event in the pathogenesis of asthma. The toxic components produced by eosinophils are thought to be important in inducing damage and dysfunction of bronchial mucosa [17]. Evidence suggests that recruitment of eosinophils into sites of inflammation is a multifractorial and multistep process, in which eosinophil-endothelial 
Table 1 Characteristics of study subjects and healthy volunteers

\begin{tabular}{|c|c|c|c|c|c|}
\hline Characteristics & Dimension & $\begin{array}{c}\text { Healthy } \\
\text { volunteers }\end{array}$ & $\begin{array}{c}\text { Steroid naïve } \\
\text { asthma }\end{array}$ & $\begin{array}{c}\text { Stable ICS-treated } \\
\text { asthma }\end{array}$ & $\begin{array}{c}\text { Unstable ICS- treated } \\
\text { asthma }\end{array}$ \\
\hline Number of patients & & 12 & 14 & 16 & 16 \\
\hline Sex & $\mathrm{F} / \mathrm{M}$ & $6 / 6$ & $8 / 6$ & $9 / 7$ & $10 / 6$ \\
\hline Age & Years & $25.40 \pm 5.20$ & $25.00 \pm 6.30$ & $39.50 \pm 10.70$ & $45.80 \pm 7.30$ \\
\hline Duration of symptoms & Years & & $2.71 \pm 1.08^{+\Delta}$ & $10.80 \pm 6.20^{* \Delta}$ & $17.06 \pm 6.50^{*^{+}}$ \\
\hline Baseline FEV ${ }_{1}$ & $\%$ pred & $102.50 \pm 9.1^{+\Delta}$ & $89.20 \pm 12.00^{\Delta}$ & $80.80 \pm 7.10^{\Delta}$ & $51.50 \pm 11.70^{*+}$ \\
\hline $\mathrm{FEV}_{1} / \mathrm{FVC}$ ratio & $\%$ & $86 \pm 7$ & $73 \pm 8$ & $64 \pm 10$ & $56 \pm 12$ \\
\hline $\begin{array}{l}\text { Serum total lgE } \\
\text { concentration }\end{array}$ & $\mathrm{kU} / \mathrm{L}$ & $61.08 \pm 25.50^{*}$ & $248.4 \pm 202.3$ & $232.5 \pm 79.0$ & $318.0 \pm 98.0$ \\
\hline Blood eosinophil count & cells $/ \mathrm{mm}^{3}$ & $56 \pm 22^{*+\Delta}$ & $212 \pm 88$ & $281 \pm 73$ & $302 \pm 95$ \\
\hline $\mathrm{F}_{\text {ENO }}$ & $\mathrm{ppB}$ & $15.80 \pm 5.06^{*}$ & $75.21 \pm 37.13^{+}$ & $39.40 \pm 12.50^{* \Delta}$ & $64.70 \pm 25.04^{+}$ \\
\hline Eotaxin-1 (EBC) & $\mathrm{pg} / \mathrm{ml}$ & $6.24 \pm 0.70^{*+\Delta}$ & $9.70 \pm 1.70^{\Delta}$ & $10.45 \pm 2.00^{\Delta}$ & $17.97 \pm 3.60^{*+}$ \\
\hline ECP (serum) & $\mu g / l$ & $3.87 \pm 0.81^{*}$ & $13.21 \pm 4.56$ & $12.80 \pm 3.50^{\Delta}$ & $21.90 \pm 8.40^{*+}$ \\
\hline ICS & $\mu \mathrm{g} /$ day & & & $359 \pm 128$ & $1078 \pm 269$ \\
\hline \multicolumn{6}{|l|}{ Positive SPT } \\
\hline mite/cat/moulds & & & $14 / 2 / 3$ & $14 / 4 / 4$ & $15 / 4 / 6$ \\
\hline
\end{tabular}

Data are presented as medians (ranges)

$\mathrm{FEV}_{1}$ - forced expiratory volume in one second

* Values significantly different from patients with steroid-naïve asthma, $p<0.05$

+ Values significantly different from patients with stable, ICS-treated asthma, $p<0.05$

${ }^{\Delta}$ Values significantly different from patients with unstable, ICS-treated asthma, $p<0.05$

ICS - inhaled corticosteroids (Fluticasone propionate equivalent)

SPT - skin prick tests (number of patients)

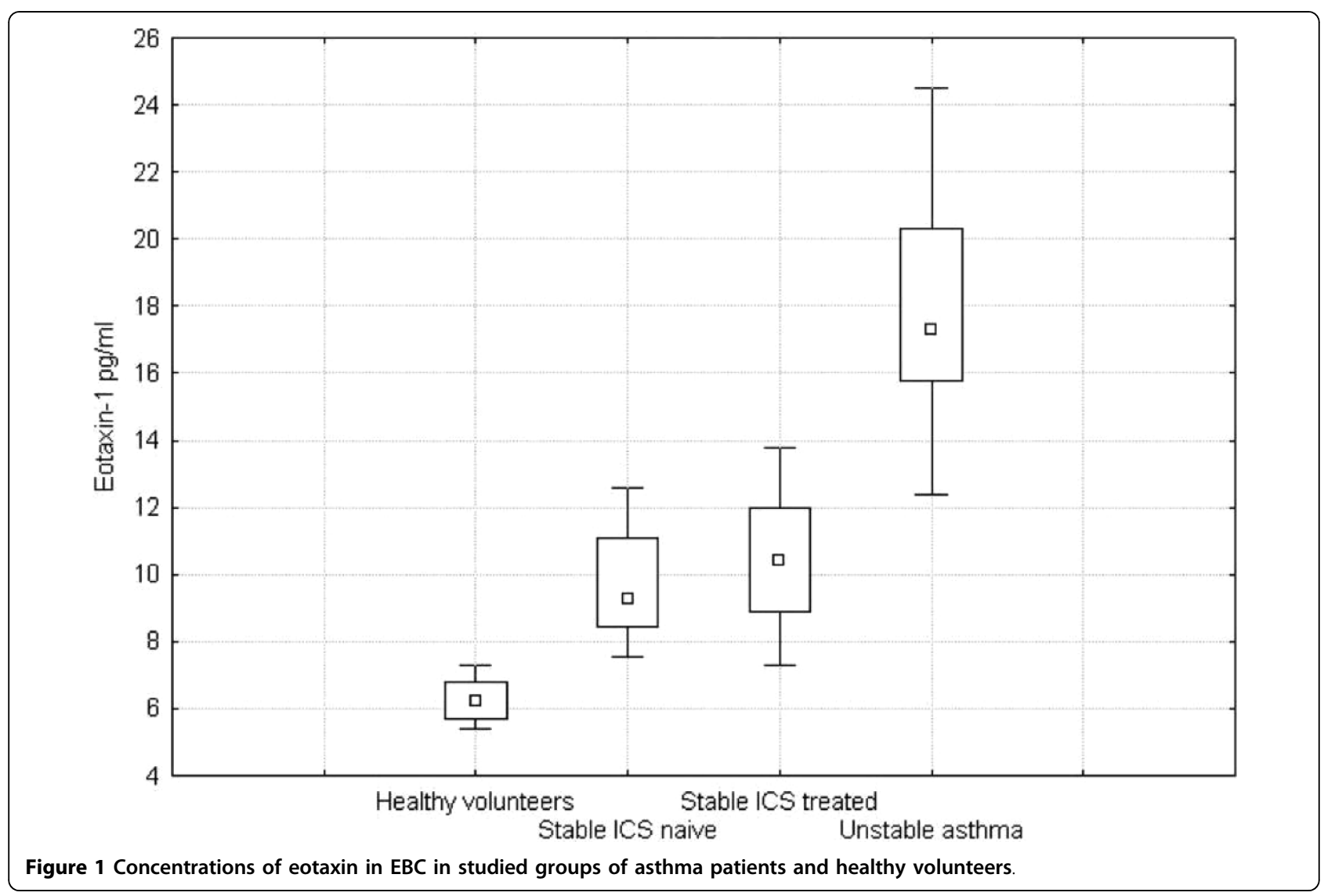




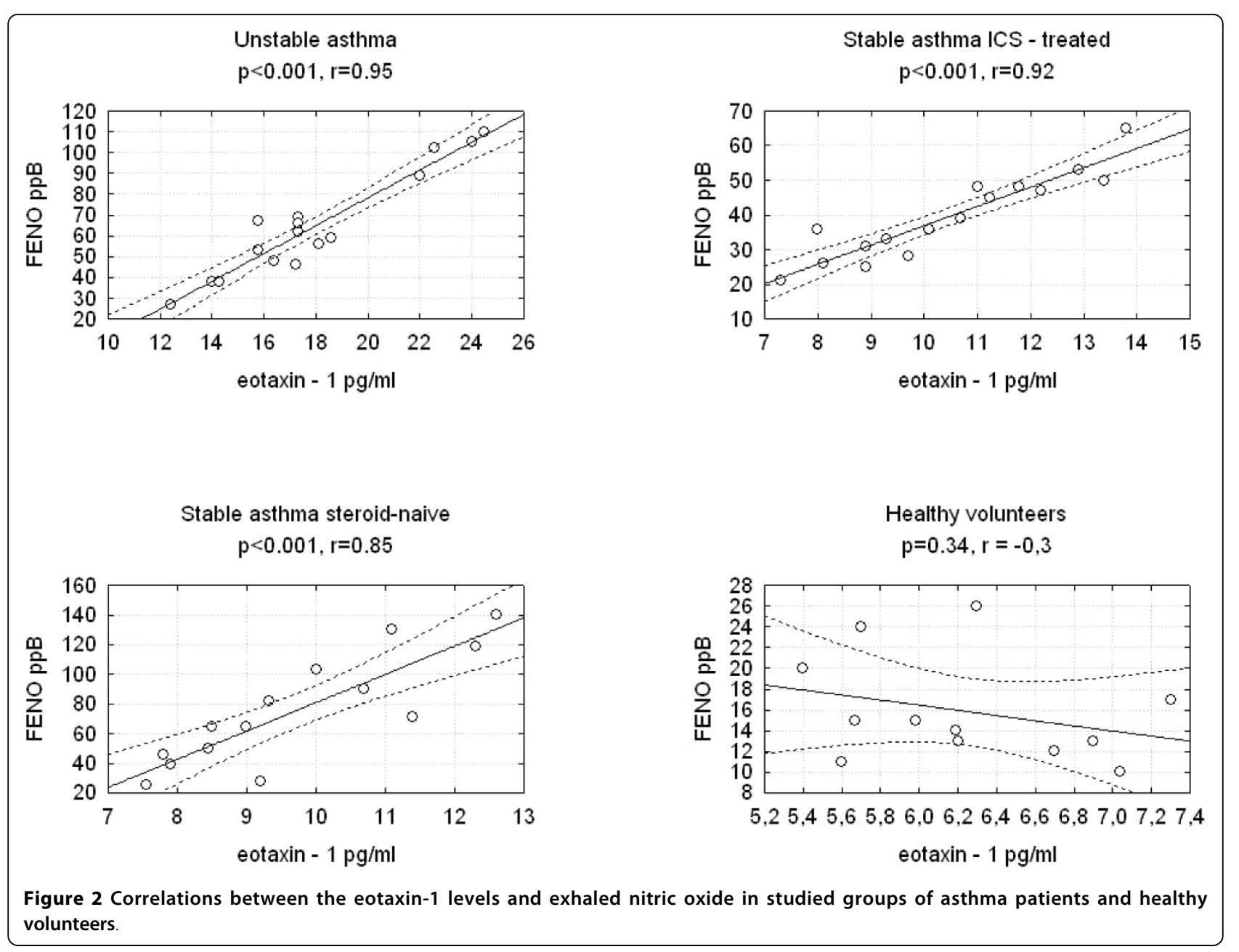

interactions through adhesion molecules, and local generation of chemotactic agents that direct cell migration into the inflamed airways, play an important role [18]. Therefore, adhesion molecules and chemokines are crucial mediators in selective eosinophil accumulation. In asthmatic patients, a relevant but variable correlation between blood eosinophilia and degree of asthma severity or bronchial hyperreactivity can be observed [19].

Eotaxin is the most specific and the strongest factor which can affect the function of eosinophil. The effect of eotaxin can be observed at each stage of the life cycle of eosinophil, and therefore plays a very important role in the development of allergic reaction. This chemokine is responsible for the release of progenitors of eosinophils from the bone marrow, and, together with IL-5, increases the count of mature forms in peripheral blood. The consequence of these processes is peripheral and tissue eosinophilia [20]. The count of eosinophils in an infiltrated organ is proportional to the concentrations of eotaxin in the site. Eotaxin is responsible for retardation of the apoptosis of eosinophils, and eotaxin interaction with a receptor leads to their activation and degranulation [2]. Eotaxin can also cause migration of mast cells [21] and basophils [22].

Those human cells which can produce eotaxin are the airway epithelium, endothelial cells, lymphocytes, macrophages, and eosinophils, as well as airway smooth muscle cells [2]. Eotaxin as a chemotactic factor for eosinophils plays an important role in the pathogenesis of asthma. It has been shown that eotaxin concentration in plasma correlates with the degree of bronchial hyperreactivity [23]. This concentration is also higher in asthmatics during exacerbation compared with patients with stable disease [24]. Higher levels of eotaxin in bronchoalveolar lavage (BAL), increased expression of mRNA for eotaxin, and an increase of eotaxin in bronchial epithelium [25] have been found in asthmatics compared with healthy volunteers.

In previous studies, the possibility of measuring of eotaxin levels in exhaled breath condensate was confirmed both in children [10] and in adults with asthma [9]. However, Leung et al did not detect any differences in eotaxin 


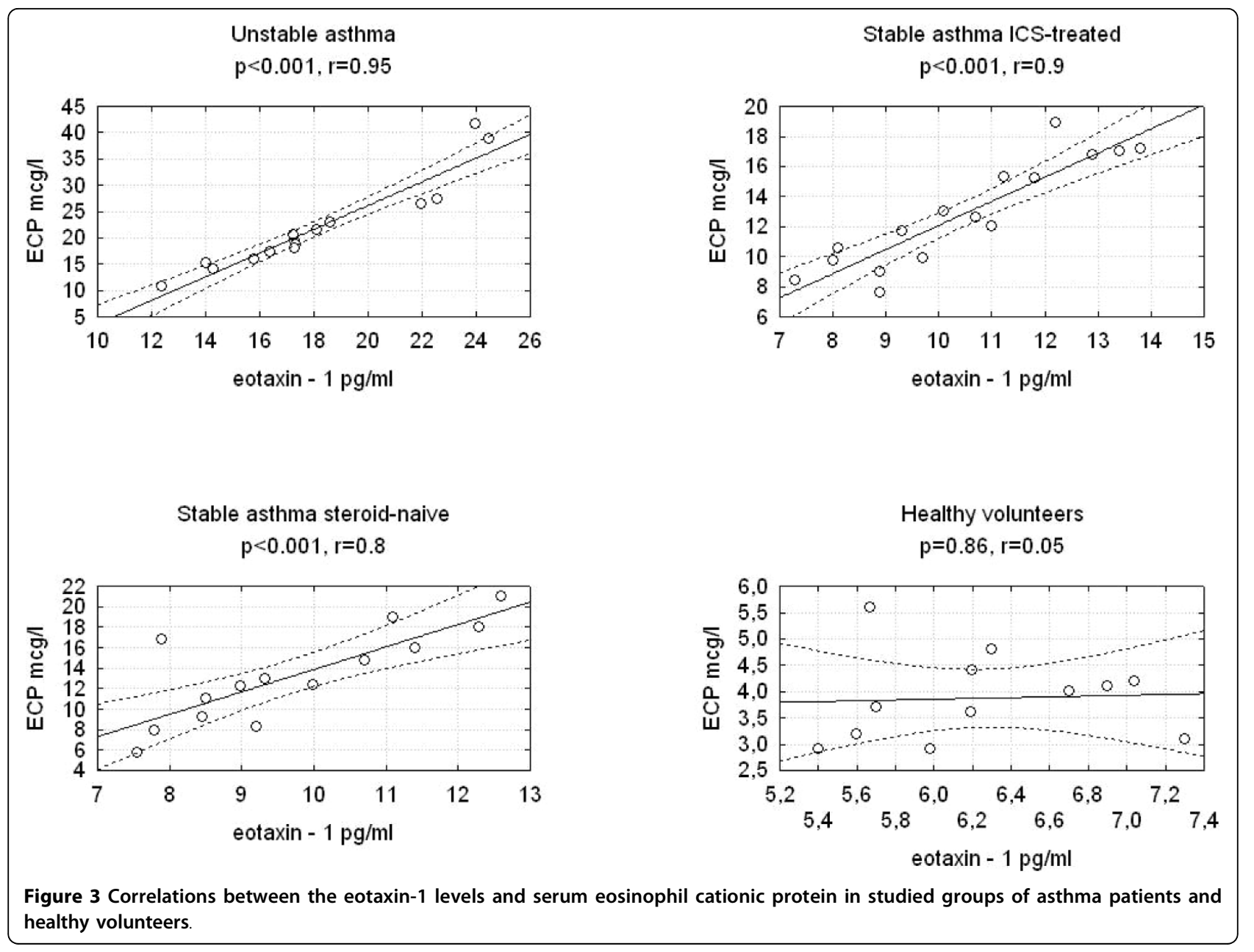

concentrations in EBC between groups of children with persistent asthma (on inhaled corticosteroids - ICS), intermittent asthma (without ICS) and healthy controls [10]. Ko et al demonstrated that eotaxin levels in EBC were higher in asthmatics than in controls, but the difference was no longer evident when, in analysis, steroid naïve mild asthma patients and healthy controls were taken into consideration [9]. It is worth noting that in any published study so far, correlations between eotaxin measurements in $E B C$ and other parameters connected with airway inflammation - which seem to be necessary for recognizing the usefulness of this parameter in the assessment of inflammation - have not been uncovered.

The results of this study have confirmed the possibility of using eotaxin-1 measurements in EBC. It is worth noting that, in this study, increased eotaxin-1 levels in EBC in all groups of asthmatic patients with different degrees of disease severity compared with healthy volunteers were revealed for the first time. These differences could be the consequence of performing this study in highly selected groups and the authors have taken efforts to make this selection as defined as has been possible. By contrast, in the previouly cited studies, the differences between studied groups could have been too minor, and these studies were performed both on atopic and nonatopic patients and healthy volunteers.

This is the first report which demonstrates the differences in eotaxin-1 levels between patients with stable and unstable asthma and healthy volunteers. Our results are the first report in which it can be shown that concentrations of eotaxin-1 in EBC significantly correlate with exhaled nitric oxide levels - a more and more appreciable criterion for the evaluation of airway inflammation - in all studied groups of asthma patients [26-28]. Eotaxin-1 also correlates with other laboratory tests commonly associated with asthma, such as elevated levels of eosinophil cationic protein (all studied groups of asthma patients) and peripheral blood eosinophilia (unstable ICS-treated asthma and steroid-naïve asthma). Population studies indicate the presence of a connection between IgE concentrations and asthma or bronchial hyperreactivity. The results of our studies did not reveal 


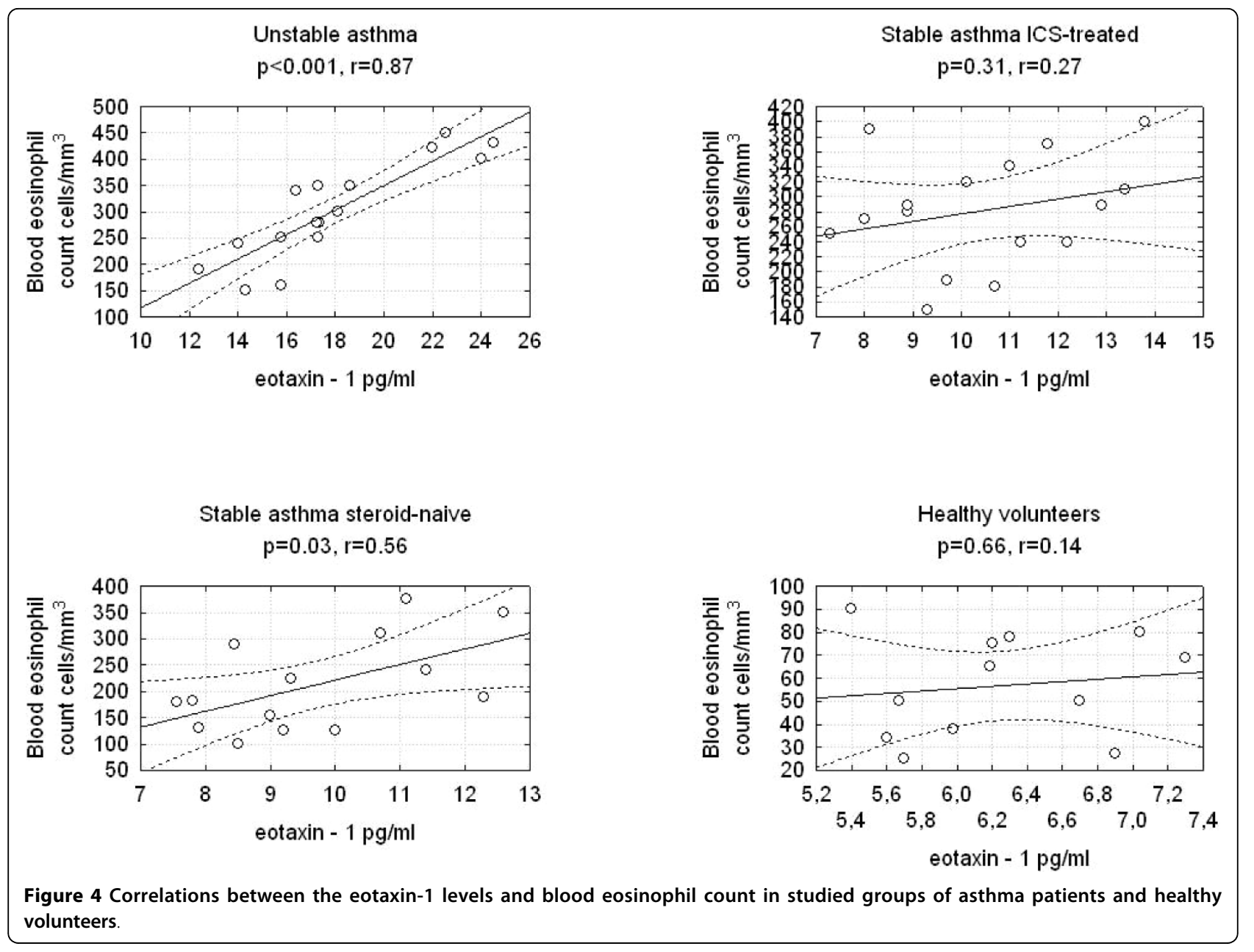

any correlations between concentrations of eotaxin- 1 in $\mathrm{EBC}$ and serum total IgE.

The results obtained here indicate the possibilities of wider use of eotaxin - 1 measurements in EBC in the assessment of airway inflammation. The correlations with other markers recognized in the evaluation of asthmatic inflammation suggest that, in this way, the possibilities of monitoring the course and treatment of asthma could be improved.
EBC examination, being simple and non-invasive, could be exploited to detect specific levels of biomarkers and monitor the severity of disease in response to appropriate prescribed therapy [15]. The analysis of EBC is still in the experimental phase. Many questions concerning the lack of standardization for both the collection and analysis of EBC, the repeatability of measurements, and the effect of many factors on concentrations of EBC markers, are still not answered.

Table 2 Correlations between eotaxin concentrations in EBC and other studied parameters in the groups of asthma patients and healthy volunteers

\begin{tabular}{llllll}
\hline Studied groups & $\mathbf{F}_{\text {ENO }}$ & Serum ECP & Blood eosinophil count & Serum total IgE & Baseline FEV $_{\mathbf{1}}$ \\
\hline Healthy volunteers & $r=-0.30$ & $r=0.05$ & $r=0.14$ & $r=-0.34$ & $r=-0.52$ \\
& $p=0.34$ & $p=0.86$ & $p=0.66$ & $p=0.27$ & $p=0.08$ \\
\hline Steroid-naïve asthma & $\mathbf{r}=\mathbf{0 . 8 5}$ & $\mathbf{r}=\mathbf{0 . 8 0}$ & $\mathbf{r}=\mathbf{0 . 5 6}$ & $\mathrm{r}=-0.12$ & $\mathrm{r}=-0.18$ \\
& $\mathbf{p}<\mathbf{0 . 0 0 1}$ & $\mathbf{p}<\mathbf{0 . 0 0 1}$ & $\mathbf{p}=\mathbf{0 . 0 3}$ & $\mathrm{p}=0.66$ & $\mathrm{p}=0.53$ \\
\hline Stable asthma ICS-treated & $\mathbf{r}=\mathbf{0 . 9 2}$ & $\mathbf{r}=\mathbf{0 . 9 0}$ & $\mathrm{r}=0.27$ & $\mathrm{r}=-0.17$ & $\mathrm{p}=-0.31$ \\
& $\mathbf{p}<\mathbf{0 . 0 0 1}$ & $\mathbf{p}<\mathbf{0 . 0 0 1}$ & $\mathrm{p}=0.31$ & $\mathrm{p}=0.52$ & $\mathrm{p}=0.22$ \\
\hline Unstable asthma ICS-treated & $\mathbf{r}=\mathbf{0 . 9 5}$ & $\mathbf{r}=\mathbf{0 . 9 5}$ & $\mathbf{r}=\mathbf{0 . 8 7}$ & $\mathrm{r}=-0.16$ & $\mathrm{p}=0.18$ \\
& $\mathbf{p}<\mathbf{0 . 0 0 1}$ & $\mathbf{p}<\mathbf{0 . 0 0 1}$ & $\mathbf{p}<\mathbf{0 . 0 0 1}$ & $\mathrm{p}=0.54$ & $\mathrm{p}$ \\
\hline
\end{tabular}




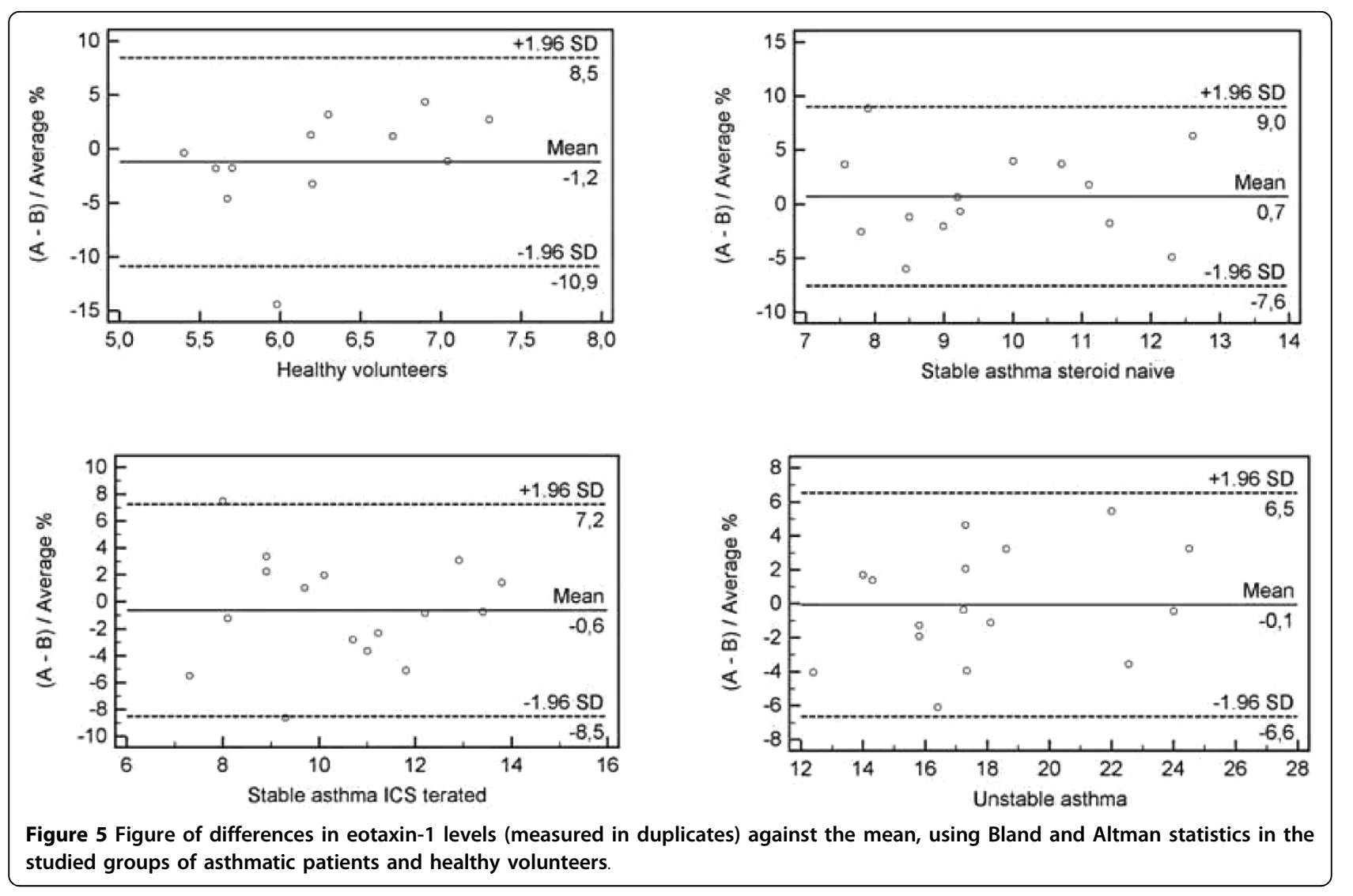

Reports from the EBC Task Force by the major American and European respiratory societies state that, although dilution may be a factor influencing EBC data, it does not appear to improve reproducibility. Because the marker used to correct the difference in the degree of dilution has not yet been established, in our study we have not taken attempts to assess the dilution of ALF in $E B C$. EBC volume does not depend on lung function parameters. There is no evidence to show that changes in airway caliber cause any difference in mediator release or dilution of $\mathrm{EBC}$; however, this point is still under investigations. Cytokine concentrations in EBC are usually quantified by ELISA kits. Several different cytokines have been described to be present in EBC: IL $4,6,10,1 \beta$, TNF- $\alpha[7,15]$. However, the concentrations of several cytokines are around the lower limits of detection. EBC collection is a completely noninvasive way of sampling the respiratory tract with good reproducibility in $\mathrm{EBC}$ volume and mediator concentration for several markers: $\mathrm{pH}, \mathrm{H}_{2} \mathrm{O}_{2}$, adenosine, 8-isoprostane $[7,15]$.

Because of the difference in methodological procedures and the effect of many factors described previously, the results (different concentrations of eotaxin-1) of our study may not be directly comparable with the results from other research groups. We suggest that in the assessment of measurements of concentrations of immunological markers, including chemokines, in EBC, the control group and analysis of observed changes between the studied groups, as well as changes in the studied parameters in time, should be taken into account.

In contrast to our previous studies, in which we suggested the beneficial effect of inhaled corticosteroids treatment on downregulation of RANTES in the airways (using EBC) [29], analysis of the results of this study does not indicate the similar effect of ICS-treatment on eotaxin-1 levels in EBC. Similar observations were published by Ko et al, which revealed that subjects on high-dose ICS had similar eotaxin levels in EBC when compared with patients on low-to-moderate doses of ICS [9]. Feltis et al did not reveal the effects of three-month treatment with ICS on eotaxin levels in BAL [4]. Similarly, Tateno et al noted that the plasma eotaxin level was not altered by inhaled or oral corticosteroid treatment [30]. However, in vitro studies have demonstrated that dexamethasone inhibition of cytokine-induced eotaxin mRNA augmentation is associated with diminished eotaxin secretion in cell cultures [31]. Further studies are needed for a better 
understanding of the effect of ICS on eotaxin in the asthmatic patients.

There are some limitations of the study. One of them is small number of patients in the studied groups. The number of patients in particular groups was based on our experiences from previous studies, in which in similar numbers of patients the possibility of obtaining statistically significant differences in studied parameters in $E B C$, as well as in peripheral blood, was revealed. Because of the small sizes of our studied groups, an analysis of the minimal number of the sample using statistical tests was not performed. The next limitation of our study worth noting is the difference in age between the studied groups of asthmatics and the healthy volunteers. These differences between studied groups are a consequence of the natural history of asthma, diagnosis at a young age, and the subsequent, sometimes severe, course of the disease. Previous studies published by Targowski et al have shown that age and sex significantly influence the serum eotaxin levels in healthy people and patients with rhinoconjunctivitis [32]. However, in the authors' opinion, the differences in age observed in this study between unstable ICS-treated asthma and stable ICS-treated asthma, as well as between steroid-naïve asthma and healthy volunteers, are small and irrelevant. Moreover, observed differences in eotaxin - 1 levels could be rather the consequence of intensification of the inflammatory process, not of differences in age, and correlate with other markers of airway inflammation.

In conclusion, we have shown that eotaxin-1 levels in exhaled breath condensate are higher in asthmatic patients with different degrees of asthma severity when compared with controls. In patients with unstable asthma, these values are significantly higher compared with subjects with stable disease and correlate with other inflammatory parameters such as exhaled nitric oxide or serum ECP. Measurements of eotaxin-1 in EBC of asthma patients may provide another useful diagnostic tool for detecting and monitoring airway inflammation. However, taking the previously described methodological limitations of our study into account, future studies are needed for better assessment of the clinical significance and the possibility of the practical usefulness of eotaxin-1 measurements in EBC.

\section{Acknowledgements}

We would like to thank all the study participants.

\section{Author details}

${ }^{1}$ Department of Allergology and Internal Medicine, Medical University of Bialystok, Poland. ${ }^{2}$ The Teaching Hospital of the Medical University of Bialystok, Poland.

\section{Authors' contributions}

ZZ conceived the trial, participated in its design, study procedures, interpretation of results, performed the statistical analysis and helped to draft the manuscript. MMT-L participated in the study procedures and helped to draft the manuscript. RS participated in the study procedures, laboratory tests and helped to draft the manuscript. EZ helped to draft the manuscript. $A B-L$ participated in study design, interpretation of results and helped to draft the manuscript. All of the authors read and approved the final manuscript.

\section{Competing interests}

The authors declare that they have no competing interests in the publication of the manuscript. This work was supported by research grant No 3-06513P from the Medical University of Bialystok, Poland.

Received: 4 March 2010 Accepted: 12 August 2010

Published: 12 August 2010

\section{References}

1. Miotto D, Christodoulopoulos P, Olivenstein R, et al: Expression of INF- $\gamma$ inducible protein; monocyte chemotactic proteins 1, 3, and 4; and eotaxin in $\mathrm{T}_{\mathrm{H}}$ 1- and $\mathrm{T}_{\mathrm{H}}$ 2-mediated lung diseases. J Allergy Clin Immunol 2001, 107:664-70.

2. Luster AD: chemotactic cytokines that mediate inflammation. $N$ Engl J Med 1998, 338:436-45.

3. Tai PC, Sun L, Spry JF: Effects of IL-5, granulocyte/macrophage colonystimulating factor (GM-CSF) and IL-3 on the survival of human blood eosinophils in vitro. Clin Exp Immunol 1991, 85:312-6.

4. Feltis BN, Reid DW, Ward C, Walters EH: BAL eotaxin and IL-5 in asthma, and the effects of inhaled corticosteroids and beta2agonist. Respirology 2004, 9:507-13.

5. Lezcano-Meza D, Negrete-Garcia MC, Dante-Escobedo M, Teran LM: The monocyte-derived chemokine is released in the bronchoalveolar lavage fluid of steady-state asthmatics. Allergy 2003, 58:1125-30.

6. Dent G, Hadjicharalambous C, Yoshikawa T, et al: Contribution of eotaxin-1 to eosinophil chemotactic activity of moderate and severe asthmatic sputum. Am J Respir Crit Care Med 2004, 169:1110-7.

7. Horvath I, Hunt J, Barnes PJ: Exhaled breath condensate: methodological recommendations and unresolved questions. Eur Respir J 2005, 26:523-48.

8. Effros RM, Dunning MB III, Biller J, Shaker R: The promise and perils of exhaled breath condensates. Am J Physiol Lung Cell Mol Physiol 2004, 287:1073-80.

9. Ko FWS, Lau CYK, Leung TF, et al: Exhaled breath condensate levels of eotaxin and macrophage-derived chemokine in stable adult asthma patients. Clin Exp Allergy 2006, 36:44-51.

10. Leung TF, Wong GWK, Ko FWS, et al: Increased macrophage-derived chemokine in exhaled breath condensate and plasma from children with asthma. Clin Exp Allergy 2004, 34:786-91.

11. Leung TF, Wong GWK, Ko FWS, et al: Clinical and atopic parameters and airway inflammatory markers in childhood asthma: a factor analysis. Thorax 2005, 60:822-6.

12. Global Initiative for Asthma: Global strategy for asthma management and prevention: NHLBI/WHO Report 2006, publication 02-3569.

13. American Thoracic Society/American Lung Association Recommendations for On-line Measurement of Exhaled Nitric Oxide in Adults and the Recommendations for On-line, Offline and Nasal Expired Nitric Oxide Measurements in Children. Am J Respir Crit Care Med 1999, 160:2104-17.

14. American Thoracic Society: Lung function testing: selection of reference values and interpretative strategies. Am Rev Respir Dis 1991, 144:1202-18.

15. Rahman I, Biswas S: Non-invasive biomarkers of oxidative stress: reproducibility and methodological issues. Redox Rep 2004, 9:125-43.

16. Multu GM, Garey KW, Robbins RA, et al: Collection and analysis of exhaled breath condensate in humans. Am Respir Crit Care Med 2001, 164:731-37.

17. Busse WW, Lemanske RF Jr: Asthma. N Engl J Med 2001, 344:350-62.

18. Gonglur U, Efeoglu T: Vascular adhesion and transendothelial migration of eosinophil leukocytes. Cell Tissue Res 2004, 318:473-82.

19. Tachimoto H, Ebisawa M, Bochner BS: Cross-talk between integrins and chemokines that influences eosinophil adhesion and migration. Int Arch Allergy Immunol 2002, 128:18-20.

20. Palframan RT, Collins PD, Williams TJ, Rankin SM: Eotaxin induces a rapid release of eosinophils and their progenitors from the bone marrow. Blood 1998, 91:2240-48. 
21. Woo CH, Jeong DT, Yoon SB, et al: Eotaxin induces migration of RBL-2H3 mast cells via a Rac-ERK-dependent pathway. Biochem Biophys Res Commun 2002, 298:392-7.

22. Uguccioni M, Mackay CR, Ochensberger B, et al: High expression of the chemokine receptor CCR3 in human blood basophils. Role in activation by eotaxin, MCP-4, and other chemokines. J Clin Invest 1997, 100:1137-43.

23. Nakamura $H$, Weiss $S T$, Israel $T$, et al: Eotaxin and impared lung function in asthma. Am J Respir Crit Care Med 1999, 160:1952-6.

24. Craing $M$, Lilly $M D$, Prescott $G$, et al: Elevated plasma eotaxin levels in patients with acute asthma. J Allergy Clin Immunol 1999, 104:786-90.

25. Ying S, Robinson DS, Meng Q, et al: Enhanced expression of eotaxin and CCR3 mRNA and protein in atopic asthma. Association with airway hyperresponsiveness and predominant co-localisation of eotaxin mRNA to bronchial epithelial and endothelial cells. Eur J Immunol 1997, 27:3507-16.

26. Smith AD, Cowan JO, Filsel $\mathrm{S}$, et al: Diagnosing asthma. Comparisons between exhaled nitric oxide measurements and conventional tests. Am J Respir Crit Care Med 2004, 169:473-8.

27. Majid $H$, Kao C: Utility of exhaled nitric oxide in the diagnosis and management of asthma. Curr Opin Pulm Med 2010, 16:42-7.

28. Zietkowski Z, Bodzenta-Lukaszyk A, Tomasiak MM, et al: Comparison of exhaled nitric oxide measurement with conventional tests in steroidnaive asthma patients. I Investig Allergol Clin Immunol 2006, 16:239-46.

29. Zietkowski Z, Tomasiak MM, Skiepko R, et al: RANTES in exhaled breath condensate of stable and unstable asthma patients. Respir Med 2008, 102:1198-202.

30. Tateno $\mathrm{H}$, Nakamura $\mathrm{H}$, Minematsu $\mathrm{N}$, et al: Plasma eotaxin level and severity of asthma treated with corticosteroid. Respir Med 2004, 98:782-90.

31. Lilly $\mathrm{CM}$, Nakamura $\mathrm{H}$, Kesselman $\mathrm{H}$, et al: Expression of eotaxin by human lung epithelial cells: induction by cytokines and inhibition by glucocorticoids. J Clin Invest 1997, 99:1767-73.

32. Targowski T, Jahnz-Rózyk K, Plusa T, et al: Influence of age and gender on serum eotaxin concentration in healthy and allergic people. J/ACI 2005, 15(4):277-82.

doi:10.1186/1465-9921-11-110

Cite this article as: Zietkowski et al:: Eotaxin-1 in exhaled breath

condensate of stable and unstable asthma patients. Respiratory Research 2010 11:110

\section{Submit your next manuscript to BioMed Central and take full advantage of:}

- Convenient online submission

- Thorough peer review

- No space constraints or color figure charges

- Immediate publication on acceptance

- Inclusion in PubMed, CAS, Scopus and Google Scholar

- Research which is freely available for redistribution 